\title{
Perfil de sensibilidade microbiana in vitro de cepas de Escherichia coli e Klebsiella pneumoniae isoladas de queijo artesanal
}

No presente estudo objetivou-se avaliar a qualidade microbiológica de queijos frescos e sua viabilidade comercial. Para tanto, foram avaliadas 80 amostras de queijos de diferentes produtores para confirmação de coliformes totais e termotolerantes. A partir das culturas positivas foram empregadas para identificação por correlação a aparência colonial, coloração de Gram y provas bioquímicas. Além disso, avaliou-se a sensibilidade antimicrobiana in vitro e o índice de resistência múltipla aos antimicrobianos. Em 97,5\% das amostras foi confirmada a presença de Escherichia coli e em 2,5\% foi identificada a existência de Klebsiella pneumoniae. As cepas de E. coli $(84,8 \%)$ evidenciaram alta sensibilidade aos antibióticos, enquanto que $100 \%$ das cepas de K. pneumoniae foram multirresitentes. Pelos resultados obtidos concluiu-se que os queijos apresentaram baixa qualidade microbiológica, deficiência das condições higiênico sanitárias, representando um risco potencial que este produto pode significar para a saúde pública.

Palavras-chave: Coliformes Termotolerantes; Queijos Coalho; Resistência; Antibiótico; Qualidade Sanitária.

\section{In vitro microbial sensitivity profile of Escherichia coli and Klebsiella pneumoniae strains isolated from artisanal cheese}

\begin{abstract}
The aim of this study was to evaluate the microbiological quality of fresh cheeses and their commercial viability. For that, 80 samples of cheeses from different producers were evaluated for total and thermotolerant coliforms. From the positive cultures were used for identification by correlation the colonial appearance, Gram staining and biochemical tests. In addition, the in vitro antimicrobial susceptibility and multiple antimicrobial resistance index were evaluated. In $97.5 \%$ of the samples of Escherichia coli was confirmed and in $2.5 \%$ the presence of Klebsiella pneumoniae was identified. E. coli strains (84.8\%) showed high sensitivity to antibiotics, whereas $100 \%$ of strains of K. pneumoniae were multiresistant. The results showed that cheeses presented low microbiological quality, deficiency of hygienic sanitary conditions, representing a potential risk that this product can mean for public health.
\end{abstract}

Keywords: Thermotolerant Coliforms; Curd Cheeses; Resistance; Antibiotic; Sanitary Quality.

Liberta Lamarta Favoritto Garcia Neres (iD Faculdade Guaraí, Brasil http://lattes.cnpq.br/0563097731032602 http://orcid.org/0000-0003-1327-605X libertalamarta@gmail.com

Júlio Cesar Ibiapina Neres (iD

Faculdade Guaraí, Brasil

http://lattes.cnpq.br/9493252013144748 http://orcid.org/0000-0002-5277-0790

biologia@iescfag.edu.br

Aluísio Vasconcelos Carvalho (iD

Faculdade Guaraí, Brasil http://lattes.cnpq.br/5200758055263996 http://orcid.org/0000-0002-3793-3133 aluisiovasconcelos@gmail.com

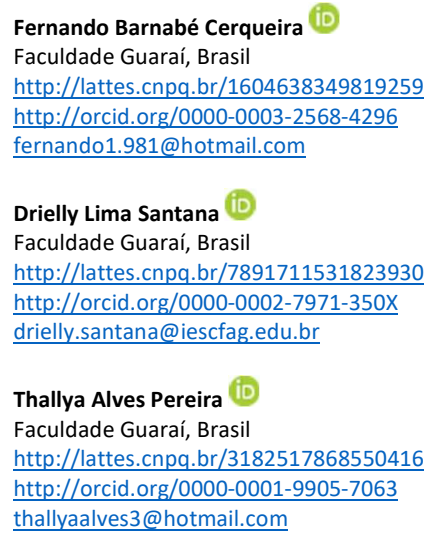

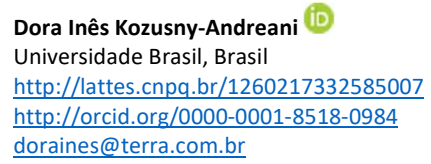

Referencing this:

NERES, L. L. F. G.; NERES, J. C. I.; CARVALHO, A. V.; CERQUEIRA, F. B.; SANTANA, D. L.; PEREIRA, T. A.; KOZUSNY-ANDREANI, D. I.. Perfil de sensibilidade microbiana in vitro de cepas de Escherichia coli e Klebsiella pneumoniae isoladas de queijo artesanal. Revista Ibero Americana de Ciências Ambientais, v.10, n.3, p.20-29, 2019. DOI: http://doi.org/10.6008/CBPC2179-6858.2019.003.0003 


\section{INTRODUÇÃO}

Os queijos artesanais são produzidos em pequenas propriedades, e em alguns casos a fabricação dos mesmos é realizada sem a adequada higienização do local e sem a pasteurização da matéria prima. Devido a sua composição nutricional e a falta dos devidos cuidados higiênico-sanitários, o queijo fresco artesanal se constituí em um importante meio para a proliferação de microrganismos patogênicos (SABIKHI et al., 2015).

Umas das características que torna o queijo tipo frescal artesanal um alimento que pode oferecer riscos à saúde humana, é o fato de ele ser constituído a base de leite cru e não passar por um processo de maturação, como também o local de sua produção, na grande maioria, ser um estabelecimento onde as condições higiênico-sanitárias são insatisfatórias (EVANGELISTA-BARRETO et al., 2016). A circulação dos patógenos por meio dos alimentos é muito comum e pode representar um risco potencial à saúde do consumidor. Portanto, a fim de evitar isso, boas práticas de higiene são necessárias em toda a cadeia de produção (RASHEED et al., 2014; MOUSSÉ et al., 2016).

Por isto, há preocupação em torno dos alimentos sobre a possibilidade de os mesmos transmitirem a população microrganismos patogênicos tais como bactérias do grupo dos coliformes, Staphylococcus coagulase positiva, Clostridium, Salmonella, entre outros, provocando o surgimento de surtos de toxinfecções alimentares de gravidade, causando desde um simples mal-estar até a ocorrência de casos fatais (RODRIGUES et al., 2016).

É necessário compreender a importância de promover adoção de boas práticas na cadeia de produção de derivados do leite, para desta forma obter produtos manufaturados de qualidade. No entanto, em algumas propriedades o processo de ordenha é realizado sem higienização, acondicionamento inadequado ou na demora da destinação do leite pode acelerar o aumento do número de microrganismos patogênicos capazes de causar a deterioração do produto inviabilizando para o consumo in natura ou provocando várias doenças aos consumidores (DANTAS et al., 2013; FONTANETTI et al., 2015)

Portanto, a população em geral deve ter ao seu alcance alimentos de qualidade, que atenda padrões estabelecidos e condições higiênicas que propiciem uma alimentação saudável para os consumidores e não um veículo de doenças transmitidas por alimentos contaminados, pondo em risco a saúde pública (SALLOTI et al., 2006).

Com a finalidade de se evitar a contaminação durante o processo de produção do queijo, deve-se observar o indicador para a presença de coliformes totais e termotolerantes nos alimentos em quantidade elevada e dentre esses patógenos, observou - se um indicador específico de contaminação, sendo esta a $E$. coli (DORES et al., 2013; GASPAROTTO et al., 2006).

A E. coli é uma das bactérias mais estudadas e representante do grupo dos coliformes termotolerantes. É caracterizada por ser uma Gram-negativa, fermentadora de lactose com consequente produção de gás e tem como consequência, além da alteração das características organolépticas do alimento, o estufamento da embalagem (TORTORA et al., 2012). E. coli é a espécie anaeróbia facultativa mais prevalente no trato gastrointestinal de humanos e animais, geralmente um micróbio inofensivo, mas 
também é uma bactéria importante do ponto de vista médico, causando uma série de doenças significativas (RASHEED et al., 2014).

A espécie Klebsiella pneumoniae é um importante patógeno oportunista que causa uma variedade de doenças infecciosas em humanos, incluindo septicemia, abscessos hepáticos, diarreia e pneumonia. É um patógeno hospitalar bem conhecido e associado ao aumento da morbidade e mortalidade dos pacientes. Além do ambiente clínico, K. pneumoniae é frequentemente encontrada em alimentos, incluindo vegetais crus, fórmulas infantis em pó, carne, peixe, laticínios, entre outros e, tem sido considerada como um importante patógeno de origem alimentar. Nos últimos anos, um número crescente de surtos de origem alimentar causados por K. pneumoniae foram relatados em diferentes países (YAO et al., 2015; DAVIS et al., 2016; GUO et al., 2016; MILANOVIC et al., 2017; ZHANG et al., 2018).

O surgimento de cepas bacterianas resistentes a antimicrobianos são de grande preocupação mundial na medicina humana (HU et al., 2013). Assim, a disseminação destas bactérias resistentes como resultado do consumo de alimentos contaminados, como carne mal cozida, frutos do mar crus, leite e produtos lácteos não pasteurizados, representa um risco a saúde pública (MILANOVIC et al., 2017). Além disso, essas bactérias podem transferir determinantes de resistência a antibióticos para outras bactérias patogênicas (TORTORA et al., 2012).

Portanto, a vigilância e o monitoramento de bactérias resistentes a medicamentos em alimentos são importantes, na implantação de estratégias de controle direcionadas para selecionar antibióticos eficazes para o tratamento de doenças infecciosas (ZHANG et al., 2018). Os patógenos resistentes mais comumente isolados da cadeia alimentar são Staphylococcus aureus, Salmonella sp. e Escherichia coli, consequência do uso extensivo de antibióticos na pecuária com a finalidade de aumentar a produção animal e, da utilização indiscriminada na terapéutica, o qual representa pressão seletiva de genes de resistência nas bactérias (GUO et al., 2016; ARENAS et al., 2018).

Considerando os aspectos descritos e, as características de produção e de comercialização do queijo frescal artesanal, no Município de Guaraí, Estado do Tocantins (Brasil), objetivou-se no presente trabalho avaliar a qualidade microbiológica de queijos frescos e sua viabilidade comercial. Para este fim foi avaliada a presença de coliformes totais, coliformes termotolerantes, Escherichia coli e Klebsiellla pneumoniae assim como a suscetibilidade destas bactérias aos antibióticos.

\section{MATERIAIS E MÉTODOS}

Foram avaliadas 80 amostras de queijos artesanais no período de junho de 2017 a abril de 2018, provenientes de oito produtores e comercializados na feira livre no município de Guaraí/TO. As amostras foram adquiridas de forma aleatória em diferentes pontos, correspondendo a dez repetições por produtor, não contendo qualquer informação sobre sua origem, data de fabricação e/ou validade.

Durante o transporte, as amostras foram mantidas em recipiente isotérmico contendo gelo e, transportadas ao laboratório para realização das análises microbiológicas. As amostras foram processadas imediatamente à chegada no Laboratório de Microbiologia do Instituto Educacional Santa Catarina, Campus 
Guaraí/TO e após o processamento foram armazenados em tubos criogênicos e transportados para o laboratório de microbiologia da Universidade Brasil em Fernandópolis-SP.

Amostras de $25 \mathrm{~g}$, de queijo tipo artesanal, foram colhidas assepticamente, as quais foram trituradas e transferidas para frasco balão Erlenmeyer com $225 \mathrm{~mL}$ de água salina peptonada estéril $(0,1 \%)$. A partir desta diluição (1:10) foram realizadas diluições seriadas. Todas as determinações foram realizadas em triplicata e para a leitura dos resultados foi utilizada a Tabela de Hoskin (SILVA et al., 2010).

As amostras de queijo diluídas em água peptonada $(0,1 \%)$ foram submetidas ao teste presuntivo: três alíquotas de três diluições foram inoculadas em uma série de três tubos de Caldo Lauril Sulfato Triptose (LST) por diluição. O LST foi usado para observação do crescimento de microrganismo, e separando aqueles que produziram gás a partir do metabolismo da lactose, no período entre 24 a $48 \mathrm{~h}$ de incubação a 35 으, sendo considerado suspeita (presuntiva) de conter coliformes. Com o teste presuntivo positivo, passou-se para o teste confirmativo.

Para a confirmação dos coliformes totais e termotolerantes, uma alçada de cada tubo considerado suspeito, foi transferida para tubos de Caldo Verde Brilhante Bile 2\% (VBB) e Caldo Escherichia coli (EC), meios seletivos contendo a lactose. A observação de crescimento com produção de gás nos tubos VBB, foi verificada entre o período de 24 a $48 \mathrm{~h}$ de incubação a 35 ํㅡ, sendo considerada confirmativa de coliformes totais. $O$ crescimento com produção de gás nos tubos EC, após $24 \mathrm{~h}$ de incubação a 45,5 으, foi considerada confirmativa da presença de coliformes termotolerantes.

De cada tubo de EC (E. coli) positivos com produção de gás, estriou-se uma alçada em placa contendo Ágar Eosina Azul de Metileno (EMB), sendo as mesmas incubadas a 35 C por 24 horas, e posteriormente foi observado se houve desenvolvimento de colônias nucleadas com centro preto, com ou sem brilho metálico. As culturas positivas foram empregadas para identificação por correlação a aparência colonial, coloração de Gram, reação oxidase, e reações bioquímicas utilizando sistema API 20E (BioMérieux).

Para avaliação da susceptibilidade antimicrobiana in vitro, utilizou-se o método de Kirby Bauer modificado, tal como recomendado pelo Clinical Laboratory Standard Institute (Clinical laboratory). Foram avaliados os antimicrobianos: tobramicina, tetraciclina, ciprofloxacina, gentamicina, sulfametoxazoltrimetropim, clorafenicol, ceftazidima, ampicilina, amicacina, aztreonam, cefoxitina, cefotaxima, ceftriaxona, cefepime, amoxicilina/ácido clavulánico e cefazolina. Os resultados foram interpretados de acordo com os protocolos estabelecidos pelo CLSI.

O índice de resistência múltipla aos antimicrobianos (IRMA) foi calculado pela razão entre o número de antibióticos aos quais o isolado foi resistente e o número de antibióticos ao qual o isolado foi exposto, sendo que o IRMA superior a 0,2 caracteriza multirresistência (KRUMPERMAN, 1983). A análise dos dados foi realizada usando o programa do software Statistical Package for the Social Sciences for Windows (SPSS) versão 15.0, como percentual, média, desvio-padrão, mínimo e máximo. 


\section{RESULTADOS E DISCUSSÃO}

Os resultados das análises para coliformes totais (Tabela 1 ) indicaram um valor mínimo de $<3,0$ e máximo de $>1100$, com variação média de 883,9 a 1036. Em relação ao desvio padrão, ocorreu uma variação entre 64 e 144,1, demonstrando uma baixa variação dos valores obtidos em relação à média.

Tabela 1: Média dos resultados do NMP/g de coliformes totais isolados de queijos frescal artesanal produzidos no Município de Guaraí, Estado do Tocantins (Brasil).

\begin{tabular}{|l|l|l|l|l|}
\hline PRODUTOR & MÉDIA & DP & MÁXIMO & MÍNIMO \\
\hline 1 & 941,0 & 108,5 & $>1100$ & 150 \\
\hline 2 & 933,0 & 111,4 & $>1100$ & 240 \\
\hline 3 & 912,5 & 126,4 & $>1100$ & 35 \\
\hline 4 & 1036,0 & 64,0 & $>1100$ & 460 \\
\hline 5 & 1014,0 & 86,0 & $>1100$ & 240 \\
\hline 6 & 1019,0 & 81,0 & $>1100$ & 290 \\
\hline 7 & 883,9 & 144,1 & $>1100$ & $<3,0$ \\
\hline 8 & 1036,0 & 64,0 & $>1100$ & 460 \\
\hline
\end{tabular}

DP: desvio padrão.

Os resultados obtidos evidenciaram excessiva contaminação microbiológica nos queijos frescal artesanal, verificando-se elevada contagem de coliformes totais, indicando provável ausência de boas práticas de higienização no processo de fabricação e manipulação do alimento. A presença de coliformes totais está associada a práticas inadequadas de higienização durante o processamento e a alta taxa de contaminação está relacionada com ausência de controle higiênico sanitário na produção desse alimento, sendo que quanto maior a quantidade de microrganismos detectada, mais precária é a condição higiênica sanitária do produto (SILVA et al., 2010; KRUMPERMAN, 1983).

A determinação de coliformes termotolerantes revelou uma variação média de 663,7 a 1036, com um valor mínimo de <3,0 e máximo >1100. Em relação ao desvio padrão, ocorreu uma variação entre 64 e 178,1, demonstrando uma baixa variação dos valores obtidos em relação à média dos resultados encontrados nas amostras, conforme tabela 2.

Tabela 2: Média de NMP/g de coliformes termotolerantes nos isolados de queijos frescal artesanal produzidos no Município de Guaraí, Estado do Tocantins (Brasil).

\begin{tabular}{|l|l|l|l|l|}
\hline PRODUTOR & MÉDIA & DP & MÁXIMO & MÍNIMO \\
\hline 1 & 782,3 & 161,9 & $>1100$ & 7,4 \\
\hline 2 & 792,8 & 157,4 & $>1100$ & $<3,0$ \\
\hline 3 & 955,0 & 97,5 & $>1100$ & 290 \\
\hline 4 & 773,3 & 139,3 & $>1100$ & $<3,0$ \\
\hline 5 & 880,7 & 146,2 & $>1100$ & $<3,0$ \\
\hline 6 & 663,7 & 178,1 & $>1100$ & $<3,0$ \\
\hline 7 & 819,9 & 147,6 & $>1100$ & $<3,0$ \\
\hline 8 & 1036,0 & 64,0 & $>1100$ & 460 \\
\hline
\end{tabular}

O valor da média das 80 amostras para o número mais provável de coliformes termotolerantes (Tabela 2) ficaram acima dos limites estabelecidos pela legislação brasileira, conforme a resolução RDC no 12, de 02 de janeiro 2001 (BRASIL, 2001) , que apresenta limite de tolerância para coliformes termotolerantes de $5 \times 10^{2} \mathrm{NMP} / \mathrm{g}$. Com base neste limite, verificou-se que a média obtida para NMP/g de termotolerantes encontrados nos queijos frescal artesanal estava fora dos padrões da legislação (Tabela 2), considerados por tanto inadequados para comercialização e, consequentemente, ao consumo humano. 
Os resultados obtidos na presente pesquisa são semelhantes aos obtidos por Ferreira et al. (2011) que constataram que $70 \%$ das amostras de queijo avaliadas apresentaram contagens superiores a legislação vigente de coliformes termotolerantes. Nunes et al. (2013) verificaram que 13\% das amostras de leite e derivados lácteos comercializadas no Distrito Federal foram rejeitadas pelas altas contagens de coliformes termotolerantes, encontradas principalmente em queijos artesanais. Garcia et al. (2013) também observou que $\mathbf{8 9 \%}$ dos queijos artesanais comercializados no município de Montes Claros/MG estavam fora dos padrões da legislação vigente brasileira. Assim como Wolupeck et al. (2012) verificaram que 78,18\% do queijo artesanal comercializado em Curitiba/PR estava com valores acima do permitido e Santana et al. (2008) constatou que as amostras apresentaram uma presença significante de alta contagem de bactérias termotolerantes em $80 \%$ das amostras analisadas em Aracaju/SE. Essa alta contagem microbiana pode ser atribuída às condições higiênicas e sanitárias inadequadas de produção e da comercialização dos queijos produzidos de maneira artesanal (PINTO et al., 2011).

Das 80 amostras avaliadas, 15\% estavam dentro dos padrões para coliformes totais e $26,25 \%$ para coliformes termotolerantes. No entanto, verificou-se, que $85 \%$ apresentaram contagens de coliformes totais e 73,75 \% com coliformes termotolerantes acima dos padrões exigidos pela legislação (BRASIL, 2011). Em $97,5 \%$ das amostras foi confirmada a presença de $E$. coli (Figura $1 \mathrm{~A}$ ) e em $2,5 \%$ foi identificada a presença de Klebsiella pneumoniae (Figura 1B). E a associação de E. coli e K. pneumoniae isoladas em queijos fabricados por três produtores é apresentada na Figura $1 \mathrm{C}$.

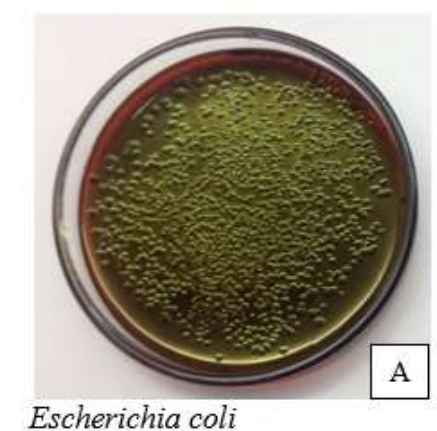

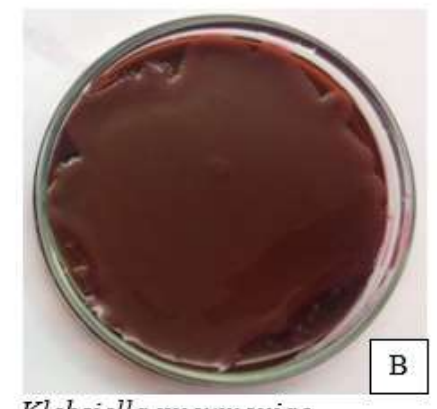

Klebsiella pneumoniae

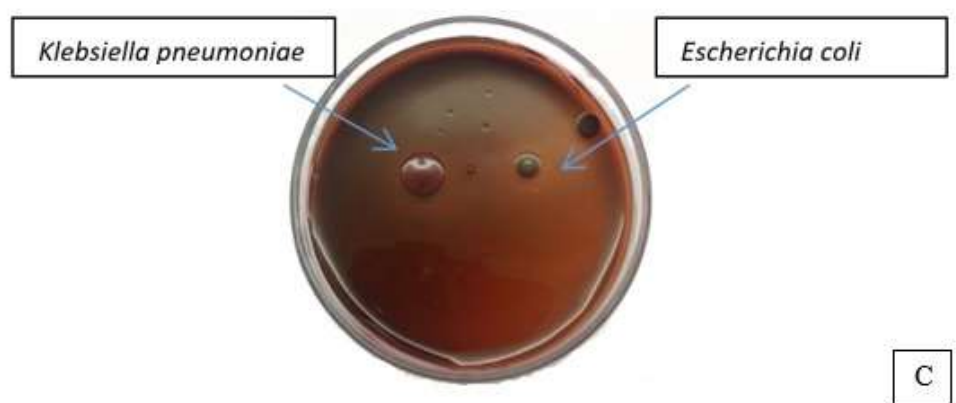

Figura 1: Colônias típicas de Escherichia coli (A), apresentando coloração verde metálico em Ágar Eosina Azul de Metileno (EMB), Klebsiella pneumoniae (B), e associação de $E$. coli e $K$. peneumoniae (C), isoladas de queijos frescal artesanal produzidos no Município de Guaraí, Estado do Tocantins (Brasil).

As bactérias de $E$. coli e $K$. peneumoniae podem eventualmente causar doença ao hospedeiro ou permanecer como um microrganismo residente com a capacidade de causar infecções oportunistas. Além disso, os genes adquiridos que conferem resistência aos antibióticos podem ser transferidos para a 
microbiota normal e induzir seleção por antibióticos sendo responsáveis pelo desenvolvimento de um grande número e variedade de infecções (FORSERG et al., 2012; RASHEED et al., 2014). Além disso, algumas espécies de enterobactérias são consideradas oportunistas em indivíduos hospitalizados e imunodeprimidos (HLOPE et al., 2014).

Para avaliação da sensibilidade/resistência aos antibióticos foram avaliadas todas as cepas de $E$. coli $(n=78)$ e de $K$. pneumoniae $(n=6)$ isoladas (Tabela 3$)$. Verificou-se maior porcentagem de cepas de $E$. coli resistentes a Ampicilina $(7,69 \%, n=6)$, seguidos por tetraciclina, cloranfenicol e sulfametoxazol-trimetropim $(5,12 \%, n=4)$, e cefotaxima $(2,56 \% n=2)$. Entre as cepas de $E$. coli não foi observado a resistência aos antibióticos aztreonam e cefazolina. Os resultados obtidos evidenciam alta sensibilidade aos antibióticos das cepas de $E$. coli contaminantes dos queijos frescal. Este perfil de bactéria provavelmente está relacionado à produção não extensiva do gado no município, implicando na exígua utilização de antibióticos. Segundo Arenas et al. (2018) o uso extensivo de antibióticos é uma prática comum para aumentar a produção animal, implicando na contaminação ambiental, de alimentos com traços do antimicrobiano e o surgimento de patógenos resistentes.

Tabela 3: Perfil de resistência aos antibióticos de Escherichia coli e Klebsiella pneumoniae isoladas de queijo fresco artesanal comercializadas no município de Guaraí/TO.

\begin{tabular}{|l|l|l|l|}
\hline \multirow{2}{*}{ Antibióticos } & \multicolumn{2}{c|}{ Porcentagem de cepas resistentes } \\
\cline { 2 - 3 } & \multicolumn{1}{|c|}{ Escherichia coli (n=78) } & \multicolumn{1}{c|}{ Klebsiella pneumoniae ( $\mathbf{n = 6 )}$} \\
\hline Aztreonam & 0 & 0 \\
Cefazolina & 0 & 0 \\
Cefepime & 1,28 & 0 \\
\hline Ceftriaxona & 1,28 & 0 \\
\hline Tobramicina & 1,28 & 16,66 \\
\hline Ciprofloxacina & 1,28 & 16,66 \\
\hline Ceftazidima & 1,28 & 16,66 \\
\hline Gentamicina & 1,28 & 50,00 \\
\hline Amoxicilina/ácido clavulánico & 1,28 & 50,00 \\
\hline Amicacina & 2,56 & 50,00 \\
Cefotaxima & 2,56 & 50,00 \\
\hline Cefoxitina & 3,84 & 50,00 \\
\hline Tetraciclina & 5,12 & 50,00 \\
\hline Sulfametoxazol-trimetropim & 5,12 & 33,33 \\
\hline Clorafenicol & 5,12 & 83,33 \\
\hline Ampicilina & 7,69 & 83,33 \\
\hline
\end{tabular}

As maiores porcentagens de cepas de Klebsiella pneumoniae resistentes aos antibióticos foram verificadas para ampicilina e clorafenicol $(83,33 \%, n=5)$, tetraciclina, amicacina, cefotaxima, cefoxitina, amoxicilina/ácido clavulánico $(50 \%, n=3)$ e sulfametoxazol-trimetropim $(33,33 \%, n=2)$. Todas as cepas apresentaram sensibilidade a aztreonam, ceftriaxona, cefepime e cefazolina. Resultados semelhantes foram obtidos por Guo et al. (2016) em cepas isoladas de diferentes alimentos de origem animal. Os autores observaram resistência contra dezesseis antibióticos, a maior taxa de resistência foi observada para ampicilina $(92,3 \%)$, seguida por tetraciclina $(31,3 \%)$, trimetoprim-sulfametoxazol $(18,2 \%)$ e cloranfenicol $(10,1 \%)$. Zhang et al. (2018) verificaram que cepas de $K$. Pneumoniae, isoladas em alimentos comercializados na rua, apresentaram altos níveis de resistência à ampicilina $(82,2 \%)$, à estreptomicina $(11 / 62,17,7 \%)$ e à piperacilina $(16,1 \%)$. Estes autores afirmaram que a presença de $K$. pneumoniae multirresitentes a 
antibióticos e virulentas nos alimentos representa um perigo potencial para a saúde dos consumidores e ressaltam a importância da vigilância sanitária de K. pneumoniae em alimentos.

Na presente pesquisa as cepas de E. coli e de $K$. pneumoniae foram avaliadas quanto ao índice de multirresistência a antimicrobianos (IRMA $>0,20$ ). As cepas de $E$. coli evidenciaram baixa multirresistência (IRMA= 0,25, figura 2), correspondendo a 3,8\% ( $n=3)$. Os resultados obtidos evidenciaram que $84,8 \%$ ( $n=65$ ) das cepas de $E$. coli foram sensíveis a todos os antibióticos avaliados (IRMA=0), constatando-se baixa incidência de resistência a estes antimicrobianos.

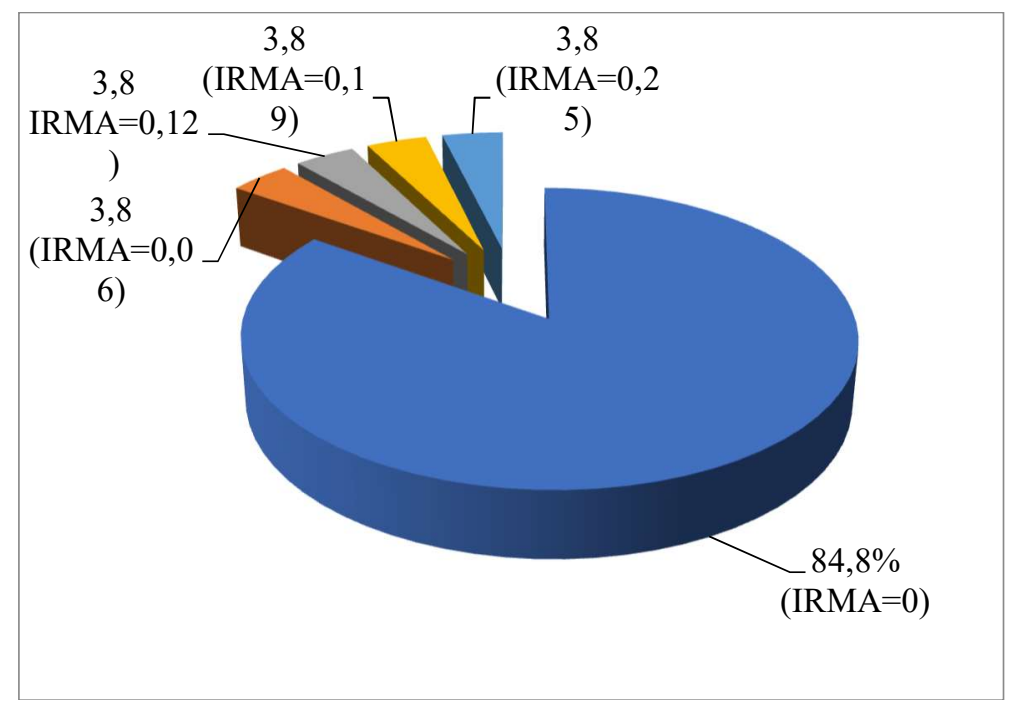

Figura 2: Frequência de Escherichia coli multirresistentes (IRMA $>0,20$ ), isoladas de queijo fresco artesanal comercializados no município de Guaraí/TO.

Portanto, a vigilância e o monitoramento de bactérias resistentes a medicamentos em alimentos é importante para implementar as estratégias de controle direcionadas e selecionar medicamentos eficazes para o tratamento (ZHANG et al., 2018). Em relação as cepas $K$. pneumoniae se verificou que $100 \%$ apresentou IRMA de 0,31 (50\%) e 0,37 (50\%) na figura 3. Os alimentos, principalmente os de origem animal, são reservatórios de K. pneumoniae resistente a antimicrobianos. Estas bactérias podem ter o potencial de se tornar um risco para a saúde pública, sendo necessárias estratégias de monitoramento e prevenção aprimoradas para melhorar o controle do surgimento e a transmissão destes microrganismos (GUO et al., 2016).

Diante dos resultados obtidos evidencia- se um problema de saúde pública devido à falta de boas práticas durante o processo de produção, presumindo que os queijos frescal artesanais comercializados pelos produtores na feira livre de Guaraí, no período da presente pesquisa, apresentaram alta contaminação por coliformes termotolerantes, E. coli e K. pneumoniae o que inviabiliza o seu consumo.

Portanto, é possível questionar a qualidade da matéria prima, os métodos empregados na fabricação e propor um conjunto de normas para adoção de boas práticas de higienização para produção do queijo frescal artesanal no município. Neste contexto, a segurança alimentar pode ajudar a prevenir e melhorar a saúde da população, assim, a higiene continua a ser um ponto-chave na luta contra doenças infecciosas, especialmente nos países em desenvolvimento (MOUSSÉ et al., 2014). 


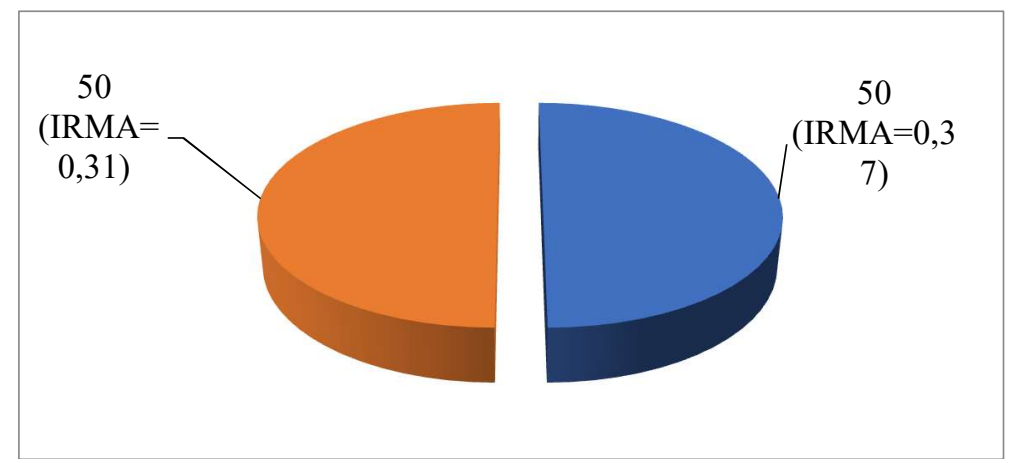

Figura 3: Frequência de Klebsiella pneumoniae multirresistentes (IRMA > 0,20), isoladas de queijo fresco artesanal comercializados no município de Guaraí/TO.

\section{CONCLUSÕES}

Diversas cepas de $E$. coli apresentaram alta sensibilidade aos antibióticos testados e um índice de multirresistência baixo, enquanto todas as cepas de $K$. pneumoniae evidenciaram multirresistência. Diante no exposto, percebe-se que $100 \%$ das cepas identificadas de E. coli e $K$. pneumoniae foram sensíveis aos antibióticos Cefazolina e Aztreonam. As amostras de queijos apresentaram baixa qualidade microbiológica, deficiência das condições higiênicas e sanitárias, representando um risco potencial que este produto pode significar para a saúde pública. Por fim, medidas devem ser adotadas para controle do uso indiscriminado de diversos antibióticos no tratamento terapêutico, evitando o surgimento de bactérias multirresistentes. Além disso, permite rastrear casos de susceptibilidade aos antimicrobianos em queijos artesanais.

\section{REFERÊNCIAS}

ARENAS, N. E.; MELO, V. M.. Producción pecuaria y emergência de antibiótico resistência en Colombia: Revisión sistemática. Infectio, v.22, n.2, p.110-119, 2018.

BRASIL. Ministério da Saúde. Resolução RDC n.12: Aprova o Regulamento Técnico sobre os Padrões Microbiológicos para Alimentos. Brasília: DOU, 2001.

DANTAS, D. S.; ARAÚJO, A. M.; SANTOS, J. O.; SANTOS, R. M. S.; RODRIGUES, O. G.. Qualidade microbiológica do queijo de coalho comercializado no município de Patos, Estado da Paraíba. Agropecuária Científica no Semiárido, v.9, n.3, p.110-118, 2013.

DAVIS, G. S.; PRICE, L. B.. Recent research examining links among Klebsiella pneumoniae from food, food animals, and human extraintestinal infections. Current environmental health reports, v.3, n.2, p.128-135, 2016.

DORES, M. T. D.; DIAS, R. S.; ARCURI, E. F.; NOBREGA, J. E. D.; FERREIRA, C. L. D. L. F.. Enterotoxigenic potential of Staphylococcus aureus isolated from Artisan Minas cheese from the Serra da Canastra/MG, Brazil. Food Science and Technology, v.33, n.2, p.271-275, 2013.

EVANGELISTA-BARRETO, N. S.; SANTOS, G. C. F.; SOUZA, J. S.; BERNARDES, F. S.; SILVA, I. P.. Queijos artesanais como veículo de contaminação de Escherichia coli e estafilococos coagulase positiva resistentes a antimicrobianos. Revista Brasileira de Higiene e Sanidade Animal, v.10, n.1, p.55-67, 2016.
FERREIRA, R. M.; SPINI, J. D. C. M.; CARRAZZA, L. G.; SANT'ANA, D. S.; OLIVEIRA, M. T.; ALVES, L. R.; CARRAZZA, T. G.. Quantificação de coliformes totais e termotolerantes em queijo Minas Frescal artesanal. Pubvet, v.5, p.1019-1026, 2011.

FONTANETTI, M. M.; GHEDIN, G. L.; DEBONI, C. N.; LIMA, H. G.; TIMM, C. D.. Qualidade microbiológica de queijo mussarela em peça e fatiado. Semina: Ciências Agrárias, v.36, n.3, 2015.

FORSBERG, K. J.; REYES, A.; WANG, B.; SELLECK, E. M.; SOMMER, M. O. A.; DANTAS, G.. The Shared antibiotic resistome of soil bacteria and human pathogens. Science, v.337, n.6098, p.1107-1111, 2012.

GARCIA, J. K. S.; PRATES, R. P.; FARIAS, P. K. S.; GONÇALVES, S. F.; SOUZA, C. N.. Qualidade microbiológica de queijos frescos artesanais comercializados na região do norte de Minas Gerais. Caderno de Ciências Agrárias, v.8, n.2, p.5865, 2016.

GASPAROTTO, P. H. G.; ROCHA, C. S.; GRECELLÉ, C. B. Z.. Quantificação de coliformes totais e fecais pela técnica do NMP em amostras de água do município de Ji-Paraná. Ciência \& Consciência, v.1, n.2, 2006.

GUO, Y.; ZHOU, H.; QIN, L.; PANG, Z.; QIN, T.; REN, H.; ZHOU, J.. Frequency, Antimicrobial Resistance and Genetic Diversity of Klebsiella pneumoniae in Food Samples. PloS one, v.11, n.4, p.e0153561, 2016. 
HLOPE, S. T.; MCKERROW, N. H.. Hospital-acquired Klebsiella pneumoniae infections in a paediatric intensive care unit. South African Journal of Child Health, v.8, n.4, p.125-128, 2014.

HU, L.; ZHONG, Q.; TU, J.; XU, Y.; QIN, Z.; PARSONS, C.; PAN, J.. Emergence of blaNDM-1 among Klebsiella pneumoniae ST15 and novel ST1031 clinical isolates in China. Diagnostic microbiology and infectious disease, v.75, n.4, p.373-376, 2013.

KIRANMAYI, C. B.; KRISHNAIAH, N.; SUBHASHINI, N.; AMARAVATHI, P.; MAHESWARI, M.; RAMYA, P.. PCR analysis of mutton and chicken samples for the presence of Shiga toxigenic E. coli. Archives of Clinical Microbiology, v.2, n.4 2011.

KRUMPERMAN, P. H.. Multiple antibiotic resistance indexing of Escherichia coli to identify high-risk sources of fecal contamination of foods. Appl. Environ. Microbiol., v.46, n.1, p.165-170, 1983.

MILANOVIĆ, V.; OSIMANI, A.; AQUILANTI, L.; TAVOLETTI, S.; GAROFALO, C.; POLVERIGIANI, S.; TURRONI, S.. Occurrence of antibiotic resistance genes in the faecal DNA of healthy omnivores, Ovo-Lacto vegetarians and vegans. Molecular Nutrition \& Food Research, v.61, n.9, p.1601098, 2017.

MOUSSÉ, W.; BABA-MOUSSA, F.; ADJANOHOUN, A.; NOUMAVO, P. A.; SINA, H.; ASSOGBA, S.; BABA-MOUSSA, L.. Virulence profiles of pathogenic Escherichia coli strains isolated from street foods in Benin. International Journal of Biotechnology and Food Science, v.4, n.3, p.52-64, 2016.

NUNES, M. M.; ALENCAR MOTA, A. L. A.; CALDAS, E. D.. Investigation of food and water microbiological conditions and foodborne disease outbreaks in the Federal District, Brazil. Food control, v.34, n.1, p.235-240, 2013

PINTO, F. G. S.; SOUZA, M.; SALING, S.; MOURA, A. C. Qualidade microbiológica de queijo minas frescal comercializado no município de Santa Helena, PR, Brasil. Arquivos do Instituto Biológico, v.78, n.2, p.191-198, 2011.

RASHEED, M. U.; THAJUDDIN, N.; AHAMED, P.; TEKLEMARIAM, Z.; JAMIL, K.. Antimicrobial drug resistance in strains of Escherichia coli isolated from food sources. Revista do Instituto de Medicina Tropical de São Paulo, v.56, n.4 p.341-346, 2014.

RODRIGUES, C. R. F.; FERREIRA, L. C.. Avaliação da qualidade microbiológica de queijo Minas Padrão produzido no município de Januária/MG. Caderno de Ciências Agrárias, v.8, n.1, p.57-61, 2016.

SABIKHI, L.; BHONGLE, P. A.; KUMAR, M. H. S.. Farmstead and artisanal cheeses: Adding value to milk at the farmers' doorstep. Indian Journal of Dairy Science, v.68, n.4, 2015.

SALOTTI, B. M.; CARVALHO, A. C. F. B.; AMARAL, L. A.; VIDALMARTINS, A. M. C.; CORTEZ, A. L.. Qualidade microbiológica do queijo minas frescal comercializado no município de Jaboticabal, SP, Brasil. Arq. Inst. Biol., v.73, n.2, p.171-5, 2006.

SANTANA, R. F.; SANTOS, D. M.; MARTINEZ, A. C. C.; LIMA, A. S.. Qualidade microbiológica de queijo-coalho comercializado em Aracaju, SE. Arquivo Brasileiro de Medicina Veterinária e Zootecnia, v.60, n.6, p.1517-1522, 2008.

SILVA, N.; JUNQUEIRA, V. C. A.; SILVEIRA, N. F. A.; TANWAKI, M. H.; SANTOS, R. F. S.; GOMES, R. A. R.. Manual de métodos de análises microbiológicas de alimentos e água. 4 ed. São Paulo: Varela, 2010

TORTORA, G. J.; FUNKE, B. R.; CASE, C. L.. Microbiologia. 10 ed. Porto Alegre: Artmed, 2012.

WOLUPECK, H. L.; ROSSA, H. C. R. L. S.; BIASI, R.; MACEDO, R. E. F.. Evolução da qualidade microbiológica de queijo Minas frescal comercializado em Curitiba (PR) no intervalo de 10 anos (1999 e 2009). Revista Acadêmica: Ciência Animal, v.10, n.3, p.243-252, 2012.

YAO, B.; XIAO, X.; WANG, F.; ZHOU, L.; ZHANG, X.; ZHANG, J.. Clinical and molecular characteristics of multi-clone carbapenem-resistant hypervirulent (hypermucoviscous) Klebsiella pneumoniae isolates in a tertiary hospital in Beijing, China. International Journal of Infectious Diseases, v.37, p.107-112, 2015.

ZHANG, S.; YANG, G.; YE, Q.; WU, Q.; ZHANG, J.; HUANG, Y. Phenotypic and Genotypic Characterization of Klebsiella pneumoniae Isolated from Retail Foods in China. Frontiers in microbiology, v.9, p.289, 2018.

A CBPC - Companhia Brasileira de Produção Científica (CNPJ: 11.221.422/0001-03) detém os direitos materiais desta publicação. Os direitos referem-se à publicação do trabalho em qualquer parte do mundo, incluindo os direitos às renovações, expansões e disseminações da contribuição, bem como outros direitos subsidiários. Todos os trabalhos publicados eletronicamente poderão posteriormente ser publicados em coletâneas impressas sob coordenação da Sustenere Publishing, da Companhia Brasileira de Produção Científica e seus parceiros autorizados. Os (as) autores (as) preservam os direitos autorais, mas não têm permissão para a publicação da contribuiçãa em outro meio, impresso ou digital, em português ou em tradução. 